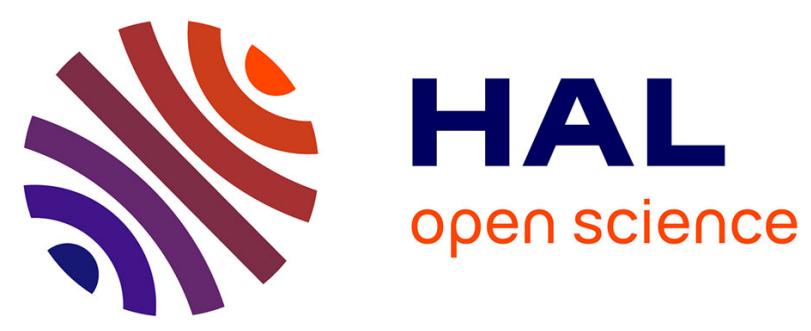

\title{
Predictive model of a DBD lamp for power supply design and method for the automatic identification of its parameters
}

\author{
Rafael Diez, Jean-Philippe Salanne, Hubert Piquet, Sounil Bhosle, Georges \\ Zissis
}

\section{To cite this version:}

Rafael Diez, Jean-Philippe Salanne, Hubert Piquet, Sounil Bhosle, Georges Zissis. Predictive model of a DBD lamp for power supply design and method for the automatic identification of its parameters. European Physical Journal: Applied Physics, 2007, 37 (3), pp.307-313. 10.1051/epjap:2007017 . hal01407395

\section{HAL Id: hal-01407395 \\ https://hal.science/hal-01407395}

Submitted on 2 Dec 2016

HAL is a multi-disciplinary open access archive for the deposit and dissemination of scientific research documents, whether they are published or not. The documents may come from teaching and research institutions in France or abroad, or from public or private research centers.
L'archive ouverte pluridisciplinaire HAL, est destinée au dépôt et à la diffusion de documents scientifiques de niveau recherche, publiés ou non, émanant des établissements d'enseignement et de recherche français ou étrangers, des laboratoires publics ou privés. 


\section{Open Archive Toulouse Archive Ouverte (OATAO)}

OATAO is an open access repository that collects the work of Toulouse researchers and makes it freely available over the web where possible.

This is an author-deposited version published in: http://oatao.univ-toulouse.fr/ Eprints ID: 16522

To link to this article : DOI:10.1051/epjap:2007017

URL : https://doi.org/10.1051/epjap:2007017

To cite this version: Diez Medina, Rafael and Salanne, Jean-Philippe and Piquet, Hubert and Bhosle, Sounil and Zissis, Georges Predictive model of a DBD lamp for power supply design and method for the automatic identification of its parameters. (2007) The European Physical Journal Applied Physics, vol. 37 ( $\mathrm{n}^{\circ}$ 3). pp. 307-313. ISSN 1286-0042

Any correspondence concerning this service should be sent to the repository administrator: staff-oatao@listes-diff.inp-toulouse.fr 


\title{
Predictive model of a DBD lamp for power supply design and method for the automatic identification of its parameters
}

\author{
R. Díez ${ }^{1, a}$, J-P. Salanne ${ }^{1}$, H. Piquet ${ }^{1, b}$, S. Bhosle ${ }^{2}$ and G. Zissis ${ }^{2}$ \\ ${ }^{1}$ Laboratoire d'Electrotechnique et d'Electronique Industrielle, Unité Mixte de Recherche INPT- \\ ENSEEIHT/CNRS. BP 7122, 2 rue Camichel, 31071 Toulouse Cedex 7, France \\ ${ }^{2}$ Centre de Physique des Plasmas et de leurs Applications de Toulouse, Unité Mixte de Recherche UPS- \\ Toulouse III /CNRS. 118 Route de Narbonne, 31062 Toulouse Cedex 4, France
}

PACS : 84.30.Jc, 52.77.-j, 52.80.Pi

\section{Predictive model of a DBD lamp}

\begin{abstract}
An electrical model for a dielectric barrier discharge (DBD) is proposed, with the aim of its application in power supply design process. An identification method, which finds the actual value of the parameters in a model, is presented. The specific modelling of a $\mathrm{XeCl}$ exciplex lamp is developed, along with the identification procedure of the parameters, using a sinusoidal and a pulsed experiment. Electrical representation of the model is done in two different simulators. The applicability of the identified model is proved with different experiments. Differences between experimental and simulated waveforms are minor, encouraging the use of the model in the construction of the converter for the DBD lamp.
\end{abstract}

\section{Introduction}

Excimer and exciplex species generation is subject of research for the production of high performance UV radiation. The generation of these species is generally achieved by a DBD (Dielectric Barrier Discharge) supplied with a high voltage generator.

In order to achieve the design of this power supply, an electrical model of the DBD lamp, considered from its terminals is studied: in a first step, some considerations are presented to justify the structure of this model. In a second step, we present the elaboration of an identification method for the parameters of the model, seeking a minimal difference between experiments and simulations. Finally, some results for sine and pulsed waveforms are shown.

Electrical simulations are performed with the commercial simulators PSIM and SABER; the parameter identification is executed with a Matlab based program built at LEEI.

\section{Experimental arrangement}

Tests are accomplished with an axisymmetrical DBD lamp as shown in figure 1: the lamp geometry is approximately, $130 \mathrm{~mm}$ length, with internal and external cylinder radius of $10 \mathrm{~mm}$ and $20 \mathrm{~mm}$ respectively, barrier thickness around $1.5 \mathrm{~mm}$. Fused silica is used as the dielectric material and the confined volume is filled with $\mathrm{Xe}$ and $\mathrm{Cl}_{2}$, to produce the $\mathrm{XeCl}$ exciplex (308 nm) [1]. The external electrode, connected to the electrical ground, is conformed by a copper lamina that wraps the exterior wall, except for a window that has a thin copper winding, allowing the UV radiation. The internal electrode is a metallic half cylinder, which is connected to the power supply output. Two different voltage waveforms are applied across the lamp: sinusoidal and pulsed, with adjustable frequency and adjustable duty cycle for the pulsed source. It is important to clarify that the experimental waveforms are not ideal, as a consequence of the parasitic elements of a step-up transformer, at the output of the converters.

\footnotetext{
${ }^{a}$ Rafael.Diez@leei.enseeiht.fr, Fax : +33 (0)5 616388 75, Tel : +33 (0)5 61588343

${ }^{\mathrm{b}}$ Hubert.Piquet@leei.enseeiht.fr, Fax : +33 (0)5 616388 75, Tel : +33 (0)5 61588261
} 


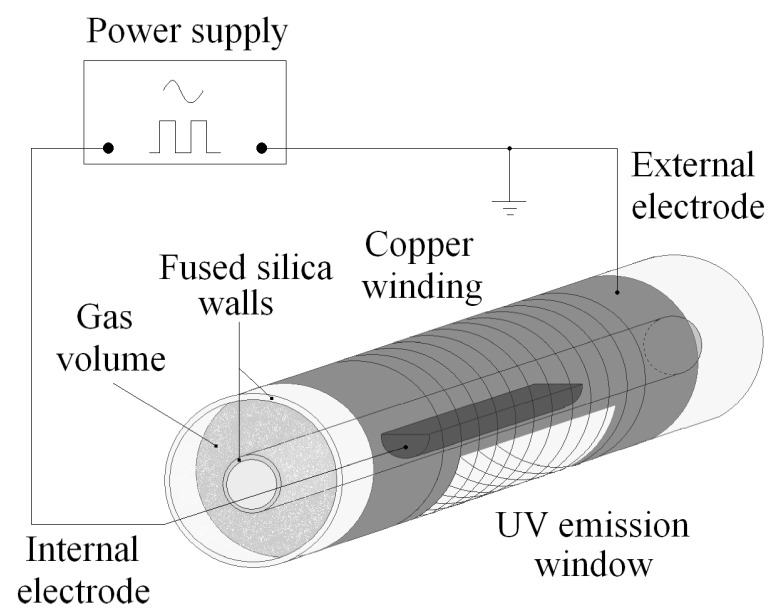

Figure 1. Experimental set-up.

\section{Electrical modelling of DBD}

Electrical simulation capacity for exciplex lamp is thought to ease the power supply design process; this point of view could be generalized and applied to the coupling of every kind of DBD to its supply. In the present work, an electrical model of the lamp is proposed as shown in figure 2, where:

- $\mathrm{C}_{1}$ symbolizes the series capacitance of internal and external dielectric barriers,

- $\mathrm{C}_{2}$ is the gas capacitance,

- $\mathrm{G}$ is the gas conductance.

The approximate value for each capacitance is calculated by mean of the classical formula for cylindrical capacitors; the dielectric constants used are, 4 for the fused silica and 1 for the gas mixture, obtaining $136 \mathrm{pF}$ for $\mathrm{C}_{1}$ and $13.07 \mathrm{pF}$ for $\mathrm{C}_{2}$. These values correspond to an ideal cylindrical capacitor, and might be a bit different for the lamp, because of its geometry and electrode structure. Nevertheless, they are good guesses for the initialization of the optimization process.

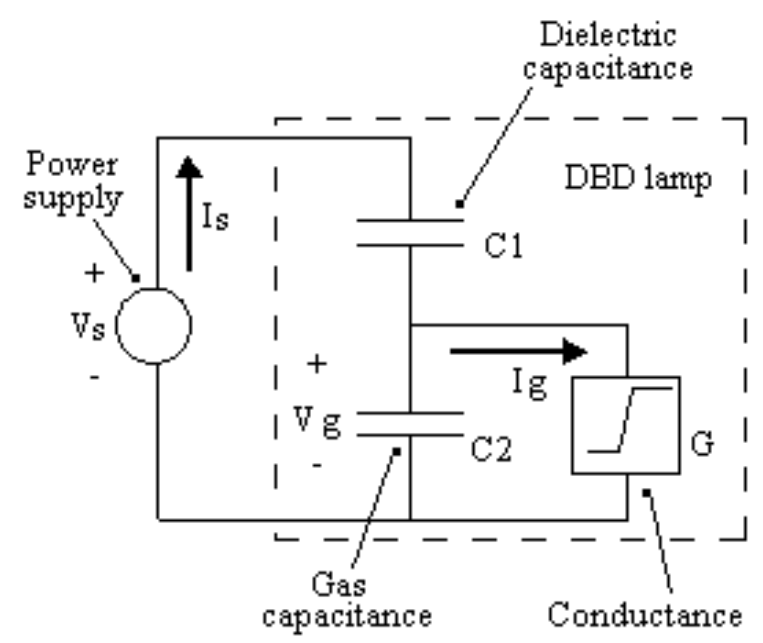

Figure 2. Electrical model of lamp. The power supply voltage and current are Vs and Is respectively.

The conduction phenomenon in the gas is represented with a branch in parallel to $C_{2}$, which behaves as a model of variable conductance, containing three terms (1). In this empirical equation, the first term represents the ionization process at the breakdown; simulation clearly shows that the contribution of this term is significant only when the conductance is near to zero and the gas voltage reaches the breakdown value. The second term symbolizes the recombination process after the breakdown. The third term establishes a relation of proportionality between the conductance and the gas current. (In steady state or low frequency conditions, when the left member $\mathrm{d} G / \mathrm{d} t$ is near zero) 


$$
\frac{\mathrm{d} G}{\mathrm{~d} t}=K_{1} \cdot\left[1+\exp \left(\frac{V_{\mathrm{th}}-\left|V_{g}\right|}{\Delta V}\right)\right]^{-1}-K_{2} \cdot G+K_{3} \cdot\left|I_{g}\right|
$$

Where:

$$
\left|I_{g}\right|=G \cdot\left|V_{g}\right|
$$

- $G$ stands for the conductance,

- $V_{\mathrm{g}}$ is the gas voltage,

- $V_{\text {th }}$ is the threshold voltage,

- $\Delta V$ is the approximation coefficient to the Heaviside function,

- $K_{1}$ is the generation coefficient,

- $K_{2}$ the extinction coefficient,

- $K_{3}$ the coefficient of proportionality between the conductance and the gas current.

This mathematical representation is derived from the Cassie [2] and Mayr [3] models, adding a breakdown term, as in the model proposed in [4]. There is an approximation of the Heaviside function with a continuous and derivable expression, enabling an analytic approach to identify the parameters of the model. It is important to comment that, the Cassie and Mayr models are not directly applicable to the current work, because those were developed to study switching arcs, differing with the regime of the DBD discharge, where a non-equilibrium plasma is present.

\section{Identification method}

With the purpose of utilizing the presented model for the design of the power supply of the lamp, it is necessary to identify the value of each parameter of the model. As the evolution of the plasma conductance is based on an equation, where each term is acting at different moment, we propose an approach based on experimental waveform analysis to achieve the identification of its parameters. Initial guesses are derived from theoretical considerations. A process based on the principle of the "model method" is proposed for this identification; it consists in the minimization of the error between experimental and time-simulation outputs for a particular input. This error can be expressed as a function of: the parameters, the input and the experimental output.

This process runs on a software developed at LEEI [5] which is divided in three main sections:

- the first part comprises the mathematical description of the electrical system using a state space model;

- the second section is based on the symbolic calculation of literal expressions for the derivatives with respect to the parameters and their representation through a transfer function or by a Matlab-Simulink model in the case of non-linear systems;

- the third and last part encloses the iterative optimization algorithm which minimizes the error function.

In the case of the DBD lamp, the model of the system is presented in figure 2 and the causality relations between the electrical quantities are as follows:

- The input of the identification process is the current delivered by the power supply; the measured waveform is injected in the simulation model,

- The output focuses on the simulation result for the voltage across the power supply; this calculated waveform is compared to the actual measured one,

- The error quantifies the difference between the simulated and the actual voltage delivered by the power supply; the normalized value of this waveform has to be minimized thanks to the adequate choice of the model parameters.

The state space model for the system is described mathematically through the following equations: (eq. 1) describes the conductance model of the gas mixture, 
(eq. 2) takes into account the gas capacitance; it is used for the computation of the gas voltage $V_{\mathrm{g}}$,

(eq. 3) links the supply to the discharge through the dielectric barriers capacitance; it permits the computation of the supply voltage $V_{\mathrm{s}}$.

$$
\begin{aligned}
& \frac{\mathrm{d} V \mathrm{~g}}{\mathrm{~d} t}=\frac{(I \mathrm{~s}-V \mathrm{~g} \cdot G)}{C_{2}} \\
& V_{\mathrm{s}}=V \mathrm{~g}+\frac{1}{C_{1}} \int I_{\mathrm{s}} \mathrm{d} t
\end{aligned}
$$

Two state variables are describing this system: the gas voltage $V_{\mathrm{g}}$ and the gas conductance $G$; the input variable $I_{\mathrm{s}}$ represents the current delivered by the power supply; the output variable $V_{\mathrm{s}}$ denotes the voltage across this source; the parameters of the system are $C_{1}, C_{2}, V_{\text {th }}, \Delta V, K_{1}, K_{2}$ and $\mathrm{K}_{3}$; the aim of this work is the identification of these ones.

This description of the system assumes that the lamp presents, a homogeneous discharge volume and smoothed out surface discharges on the dielectric surfaces. Actually, filamentary behavior is generally observed in $\mathrm{XeCl}$ lamp discharges; nevertheless, taking the variables in average value, this procedure is representative for the overall discharge description and useful for the specified purpose.

The optimization algorithm consists in two nested loops as shown in figure 3 . The internal loop is based on the minimization of error varying the parameters at every step using the "steepest-descent" or "Levenberg-Marquardt" methods [6,7]; the maximum number of steps and the error margin limits are the convergence criteria. The external loop defines which parameters will be changed in the internal loop, initially all parameters are allowed to change. Every time the internal loop returns a result, the parameters that have clearly changed and converged are fixed to their final value and then passed to the internal loop again until all parameters stay unaffected. Optionally when the process is finished the final parameters are put again into the optimization algorithm to eventually refine the results.

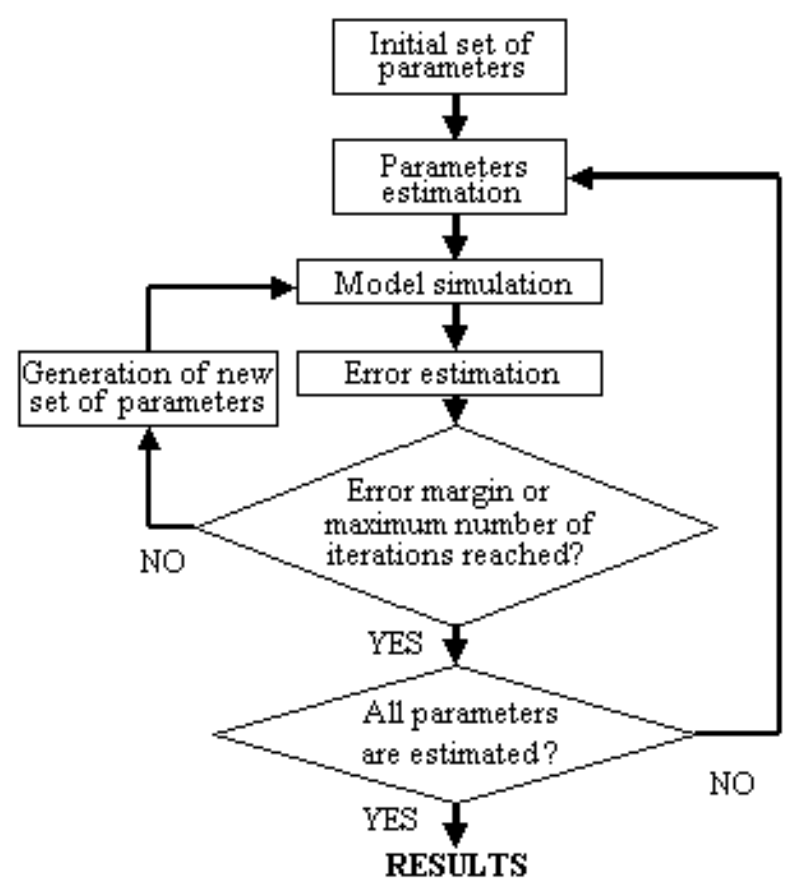

Figure 3. Error minimization algorithm used for the parameter identification

\section{Choice of initial parameters}

The identification method described is now exploited through various experimental conditions; a progressive process is proposed to build a satisfactory set of parameters for the model, obtaining really 
satisfactory results and a predictive model of the DBD lamp, with various supply conditions. In this process, the choice of the initial set of parameters is very important for its convergence; the method adopted for the determination of these initial values is presented in this section.

\subsection{Capacitance estimation}

In section 3, a theoretical calculus of both capacitors of the model has been done: their series equivalent capacitor value is $11.9 \mathrm{pF}$ and should comply with the equation (4); which describes the behaviour of the system when there is no gas discharge, since the conductance is assumed to be zero.

$$
V_{\mathrm{s}}=\frac{1}{C_{\text {eq }}} \int I_{\mathrm{s}} \mathrm{d} t
$$

In the practice, with a $100 \mathrm{kHz}$ sinusoidal supply voltage, the series capacitance value is found to be around $8.9 \mathrm{pF}$ as shown in figure 4 . Consequently, the initial value of $\mathrm{C}_{1}$ is changed to $39.81 \mathrm{pF}$ before the identification process starts; $\mathrm{C}_{2}$ remains in its theoretical value.

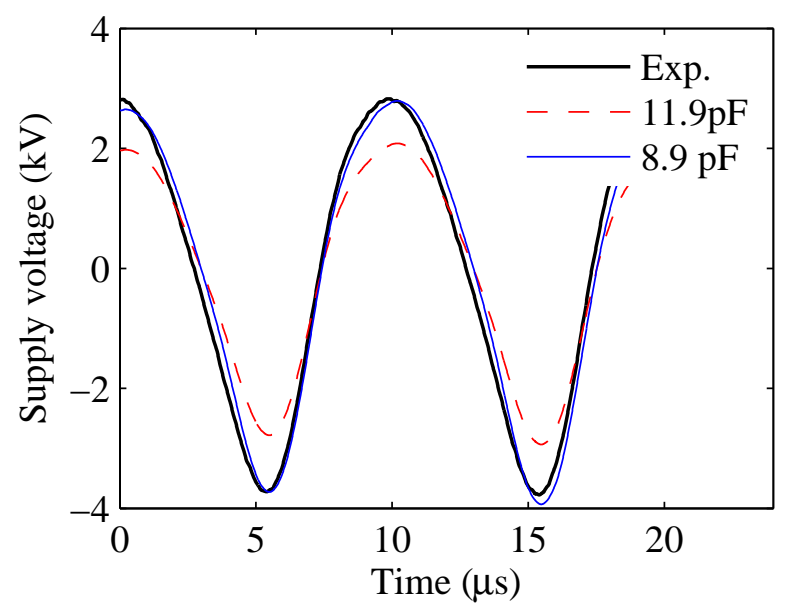

Figure 4. Experimental sine supply voltage at $100 \mathrm{kHz}$ used to evaluate the series capacitance when there is no gas breakdown. Supply voltage signals reproduced with the theoretical and actual capacitance.

\subsection{Initial parameter values of conductance model}

Using the sinusoidal experimental waveforms of voltage and current from power supply, when gas rupture is observed, and assuming the new capacitance values as correct, it is possible to calculate the gas voltage and current, and thus the gas conductance. These three new waveforms are now used, for the estimation of the initial values of the remaining parameters.

5.2.1. Threshold voltage: Using the equation (5), the gas voltage waveform is calculated (figure 5). The maximum value of this new signal will be the initial threshold voltage parameter. With several maxima, $V_{\text {th }}$ is graphically estimated to $1500 \mathrm{~V}$.

$$
V_{\text {gas }}=V_{s}-\frac{1}{C_{1}} \int I_{\mathrm{s}} \mathrm{d} t
$$




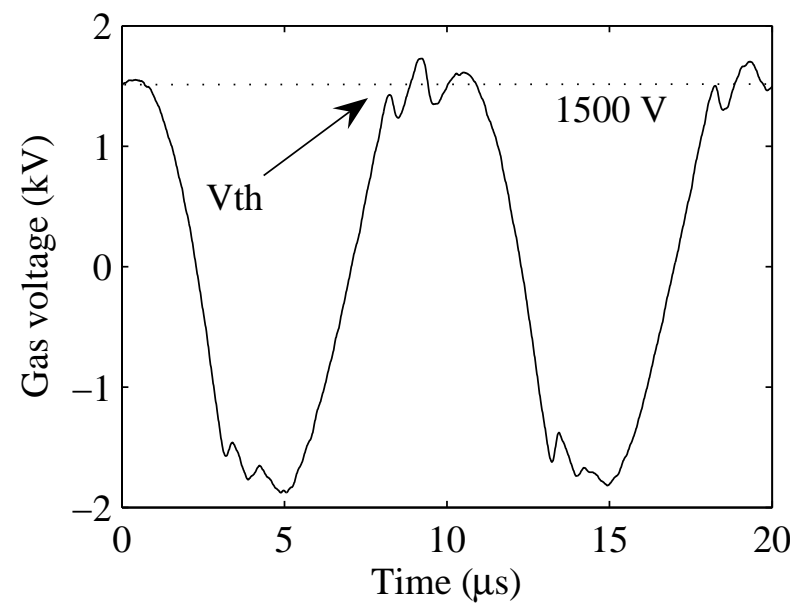

Figure 5. Gas voltage waveform calculated from initial capacitance value; used to determine the initial threshold voltage.

5.2.2. Extinction coefficient $\left(\mathrm{K}_{2}\right)$ : After the gas voltage is calculated, gas conduction current and gas conductance, are found using equations (6) and (7). The exponential decreasing behaviour is observed in the conductance (figure 6); hence the initial extinction coefficient is selected as the inverse of the decay time constant, $\mathrm{K}_{2}$ is graphically approximated to: $2.7 \times 10^{6} \mathrm{~s}^{-1}$. This initial value appears to be acceptable, when compared with data from the literature [8].

$$
\begin{array}{r}
I_{\text {gas }}=I_{s}-C_{2} \cdot \frac{\mathrm{d} V_{\text {gas }}}{\mathrm{d} t} \\
G_{\text {gas }}=\frac{I_{\text {gas }}}{V_{\text {gas }}}
\end{array}
$$

5.2.3. Coefficient of proportionality $\mathrm{I}_{\mathrm{gas}}$ vs. $\mathrm{G}_{\mathrm{gas}}\left(\mathrm{K}_{3}\right)$ : Figure 6 shows the plots of the gas conduction current and the gas conductance. Neglecting the singularities caused by the numerical calculus when the gas voltage crosses by zero, a direct relationship between those two variables is clearly seen (applying the absolute value function to the gas current). A priori the ionization caused by the breakdown of gas, must be an impulsive event, therefore, considering a quasi-static steady state operation, the second and third terms from equation (1) are considered to be of the same magnitude. In consequence $\mathrm{K}_{3}$ is estimated to: $1835\left(\mathrm{~V}^{-1} \mathrm{~s}^{-1}\right)$.

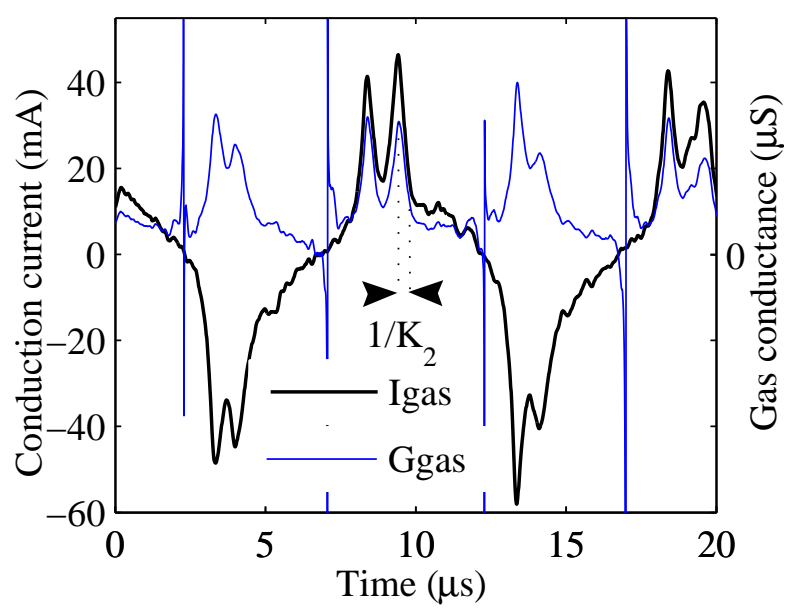

Figure 6. Gas conduction current and the gas conductance calculated from the initial estimated values of capacitances. A direct relationship between the variables is observed. 
5.2.4. Ionization parameters $\left(\Delta \mathrm{V}\right.$ and $\left.\mathrm{K}_{1}\right)$ : As commented above, the ionization process is thought to be an almost instantaneous event; if this hypothesis is valid, the approximation coefficient to the Heaviside function, $\Delta \mathrm{V}$, would tend to its minimum value; to confirm that, the initial $\Delta \mathrm{V}$ is set to 20 $\mathrm{V}$, allowing the movement in both directions but with a lower limit of $2.9 \mathrm{~V}$, which is the convergence frontier in simulations. The ionization coefficient, $\mathrm{K}_{1}$, is initialized, deriving the conductance waveform against time and taking its maximum value, then initial $\mathrm{K} 1$ is $130(\Omega \mathrm{s})^{-1}$.

\section{Identification}

The entire identification process is achieved with two experimental waveforms: a $100 \mathrm{kHz}$ sine and a $145 \mathrm{kHz}$ pulsed with a duty cycle of $60 \%$. Initially the process is applied to the sine wave, after that, the result is submitted as the input of the pulsed wave, and so forth, until the convergence is reached. Table 1 shows in rows 1 and 2, the initial value and results of the first parameter identification. To remark that $\Delta \mathrm{V}$ reach its minimal value as expected. Identification result is shown in figure $7 \mathrm{~b}$.
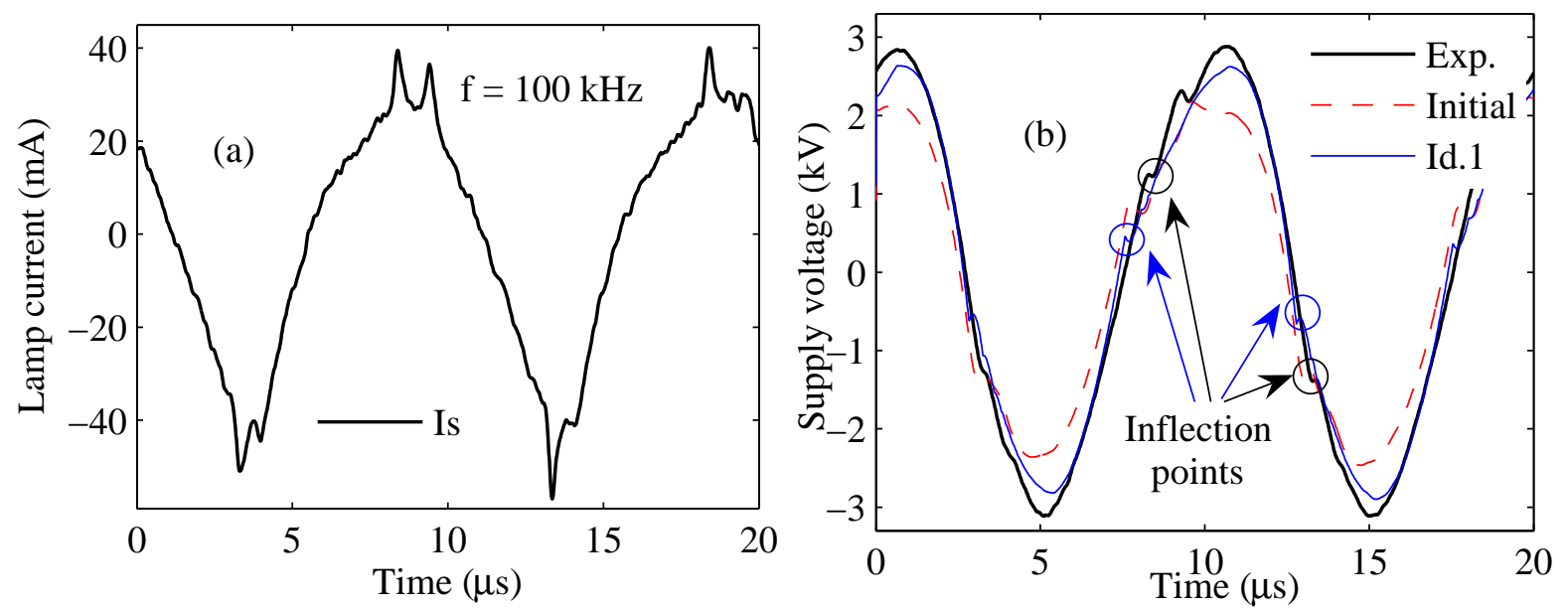

Figure 7. First identification result. Current in the lamp (a), used as the input for the identification algorithm .Comparison between experimental supply voltage and simulations obtained with initial and identified parameters (b).

Table 1. Different sets of parameters before and after identification process.

\begin{tabular}{lcccccccc}
\hline & Step & $V_{\text {th }}(\mathrm{V})$ & $\Delta V(\mathrm{~V})$ & $K_{1}\left(\mathrm{~S} \mathrm{~s}^{-1}\right)$ & $K_{2}\left(\mathrm{~s}^{-1}\right)$ & $K_{3}\left(\mathrm{~V}^{-1} \mathrm{~s}^{-1}\right)$ & $C_{1}(\mathrm{pF})$ & $C_{2}(\mathrm{pF})$ \\
\hline Initial values & Initial & 1500 & 20 & 130 & $2.7 \times 10^{6}$ & 1835 & 39.81 & 13.07 \\
First identification & Id.1 & 1270 & 2.9 & $1.79 \times 10^{3}$ & $2.7 \times 10^{6}$ & 295 & 35.07 & 11.39 \\
After $V_{\text {th }}$ increment & Id.2 & 1800 & 2.9 & $2.5 \times 10^{3}$ & $1.5 \times 10^{6}$ & 6.95 & 40.03 & 13.87 \\
Final result & Id.3 & 1800 & 2.9 & $2 \times 10^{4}$ & $1 \times 10^{6}$ & 100 & 40.03 & 13.87 \\
\hline
\end{tabular}

6.1. Adjustment of the breakdown voltage $\left(V_{\mathrm{th}}\right)$

Although the error is minimized with the initial identification, the inflection point of identified signal is lower than in the experiment (figure $7 \mathrm{~b}$ ); for this reason $V_{\text {th }}$ is manually incremented and fixed to $1800 \mathrm{~V}$, the identification process is resumed obtaining the second result shown in row 3 of table 1 . To notice that value of series equivalent capacitor corresponds to the no breakdown detected value found in subsection 5.1 .

\subsection{Ionization time}

The results obtained in last step are really good in accordance with simulation; nevertheless, $K_{1}$ constant is manually increased, diminishing the ionization time close to $10 \mathrm{~ns}$, to be in accordance with the typical DBD breakdown time, found in the literature [9]. The final step is completed with the identification of $K_{2}$ and $K_{3}$. Definitive parameters are listed in the fourth row of table 1. Figure 8 shows the results. 

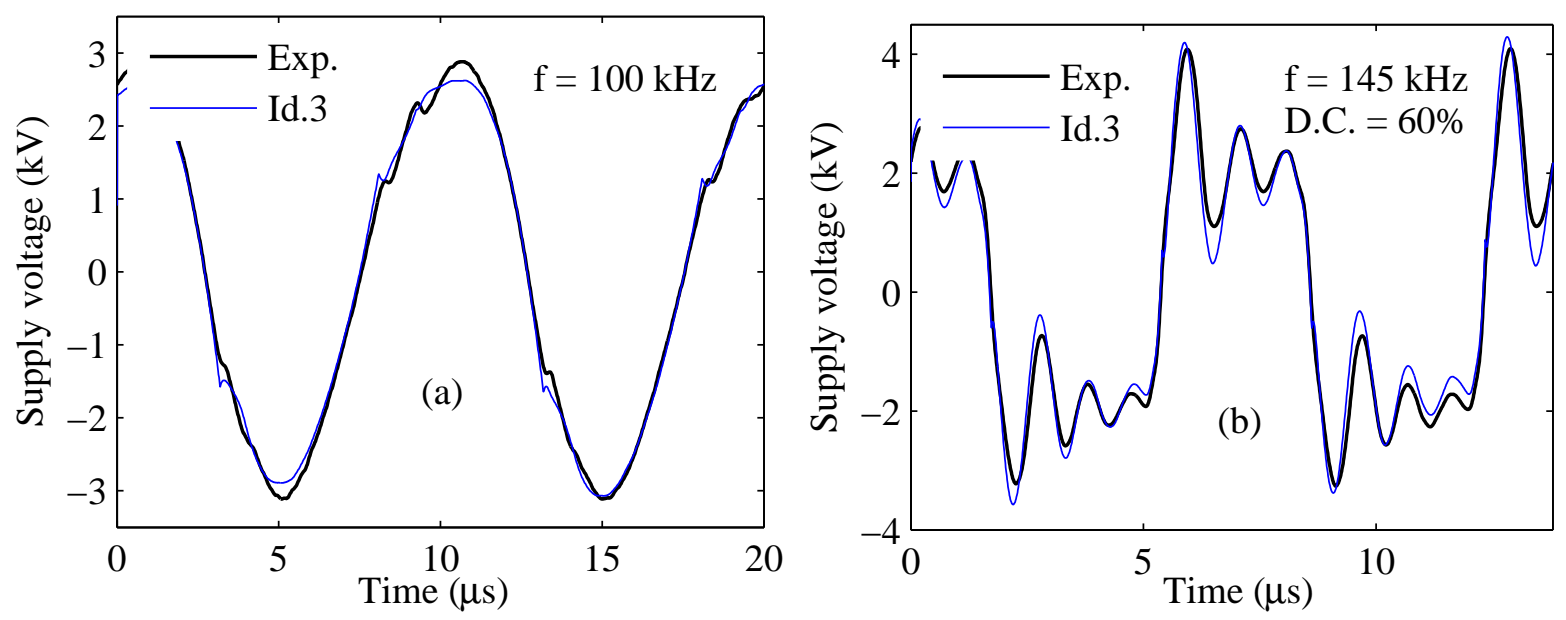

Figure 8. Final identification results. Comparison between experimental and simulated signals for, Sinusoidal experiment (a) and pulsed experiment (b).

\section{Electrical simulations}

Once the parameters have been identified, the model has to be tested for different signals; with this objective PSIM [10] and SABER [11] models are built, where the total current is the input of the system and the total voltage is the output. These models are ideal to be used with power supply design intentions. Both models work properly; only the PSIM model is presented in this paper.

\subsection{PSIM Model}

This model is presented on figure 9: it is built with an equivalent electrical circuit. The experimental input current is supplied via a SimCoupler module from Matlab-Simulink. The simulated signals like the gas voltage, the conductance, etc., are also exported to Matlab for post-processing. Figure 10 shows the quality and predictivity of the proposed model; the investigated conditions of these simulations are different than those used for identification. Sine frequencies are $110 \mathrm{kHz}$ and 127.5 $\mathrm{kHz}$; the pulsed simulations run at $145 \mathrm{kHz}$ and $170 \mathrm{kHz}$, with $20 \%$ and $27 \%$ of duty cycle respectively. We can appreciate the accuracy of the computed input voltage compared with experimental measurement for every simulation.

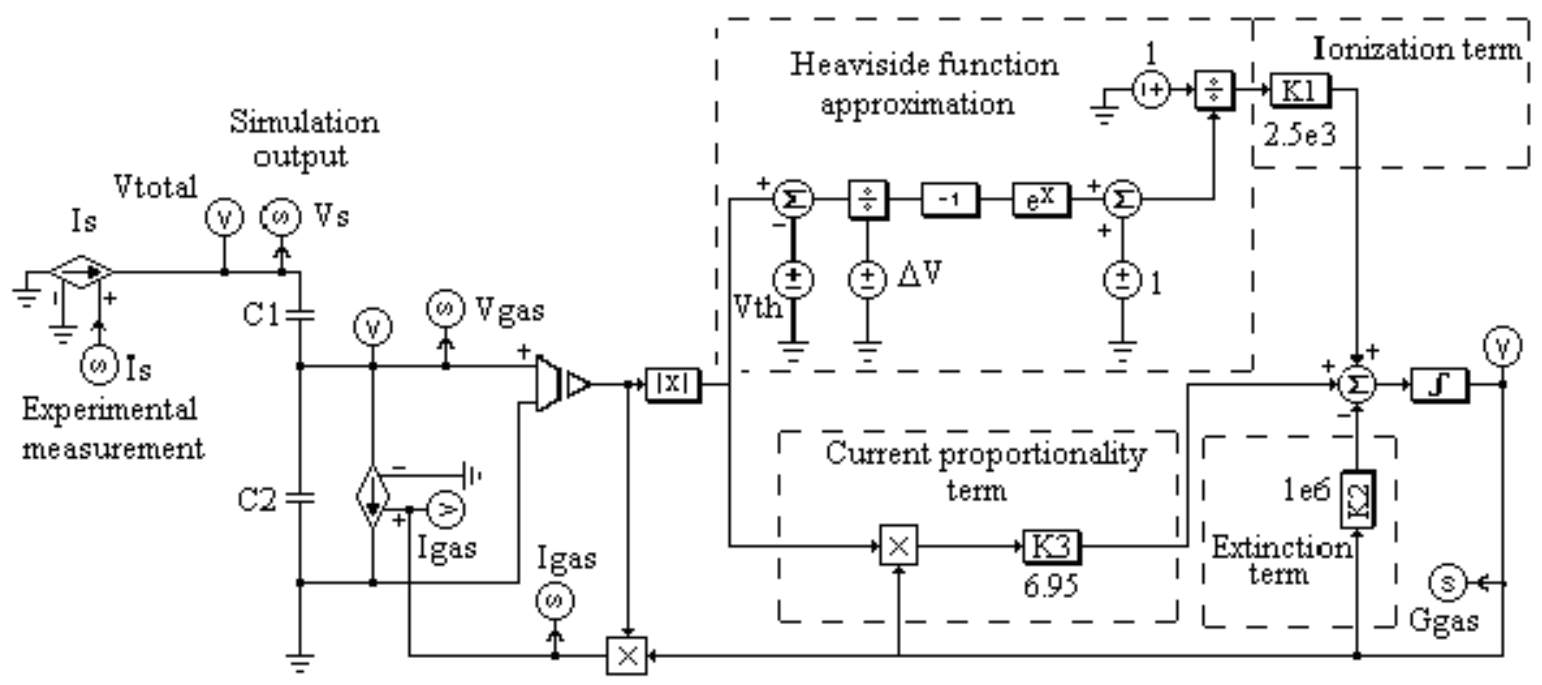

Figure 9. Electrical model of the DBD lamp, after identification is done. 

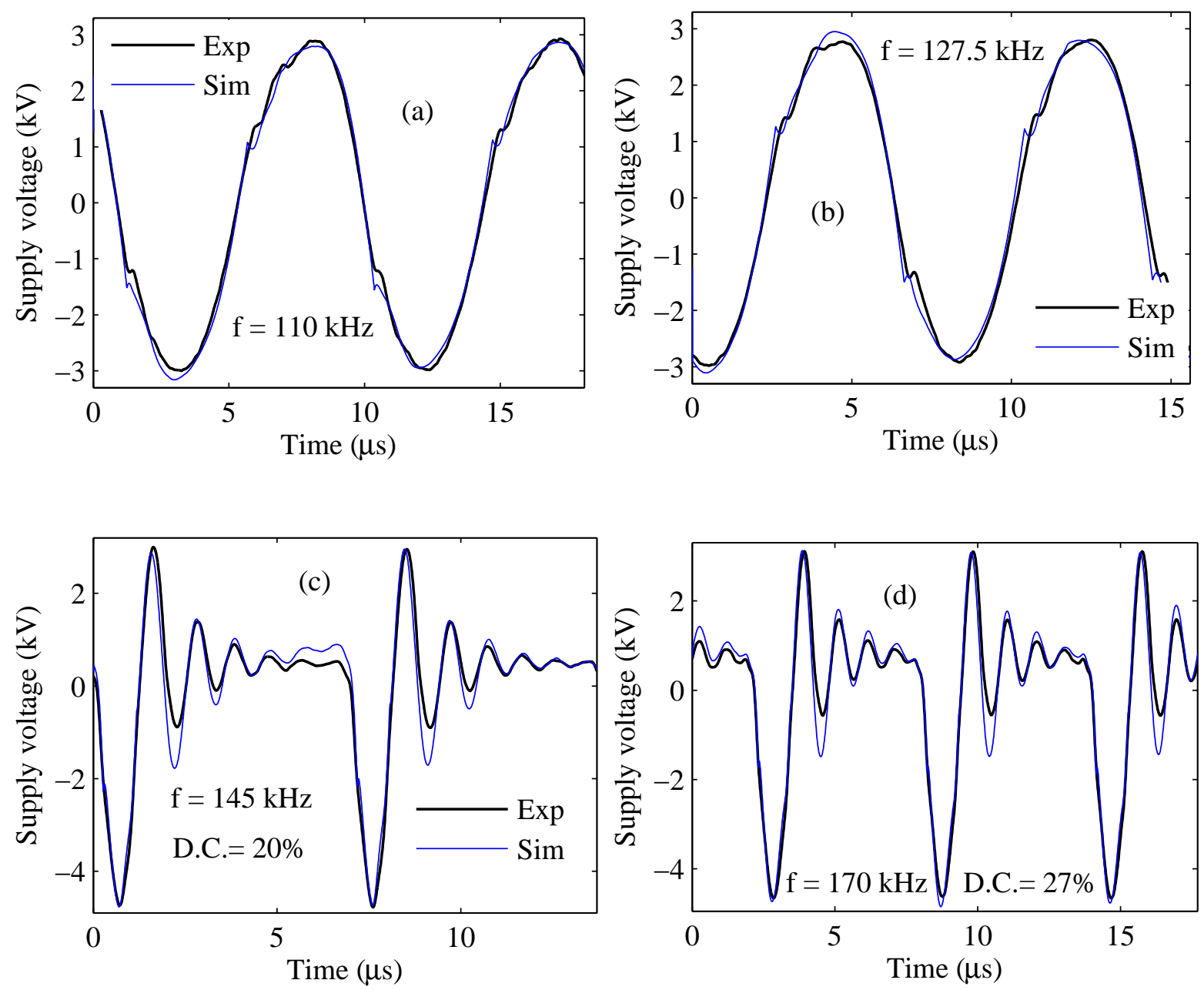

Figure 10. Experimental input voltages and simulation results with conditions different than used in identification. $110 \mathrm{kHz}$ sine wave (a), $127.5 \mathrm{kHz}$ sine wave (b), Pulsed waveforms at $145 \mathrm{kHz}$ and duty cycle of $20 \%$ (c), and frequency of $170 \mathrm{kHz}$ and duty cycle of $27 \%$ (d).

\subsection{Discussion of the conductance model}

The temporal contribution of each one of the source terms in the equation (1) is shown in figure 11a. As expected, the ionization term is impulsive with the highest amplitude, activated at the breakdown moment and it lasts around $10 \mathrm{~ns}$ approximately. Afterwards the remaining term operates (current proportionality). The similitude between the absolute value of the gas conduction current $\left|I_{\mathrm{g}}\right|$ and the computed conductance $G$ can be appreciated on figure $11 \mathrm{~b}$. 

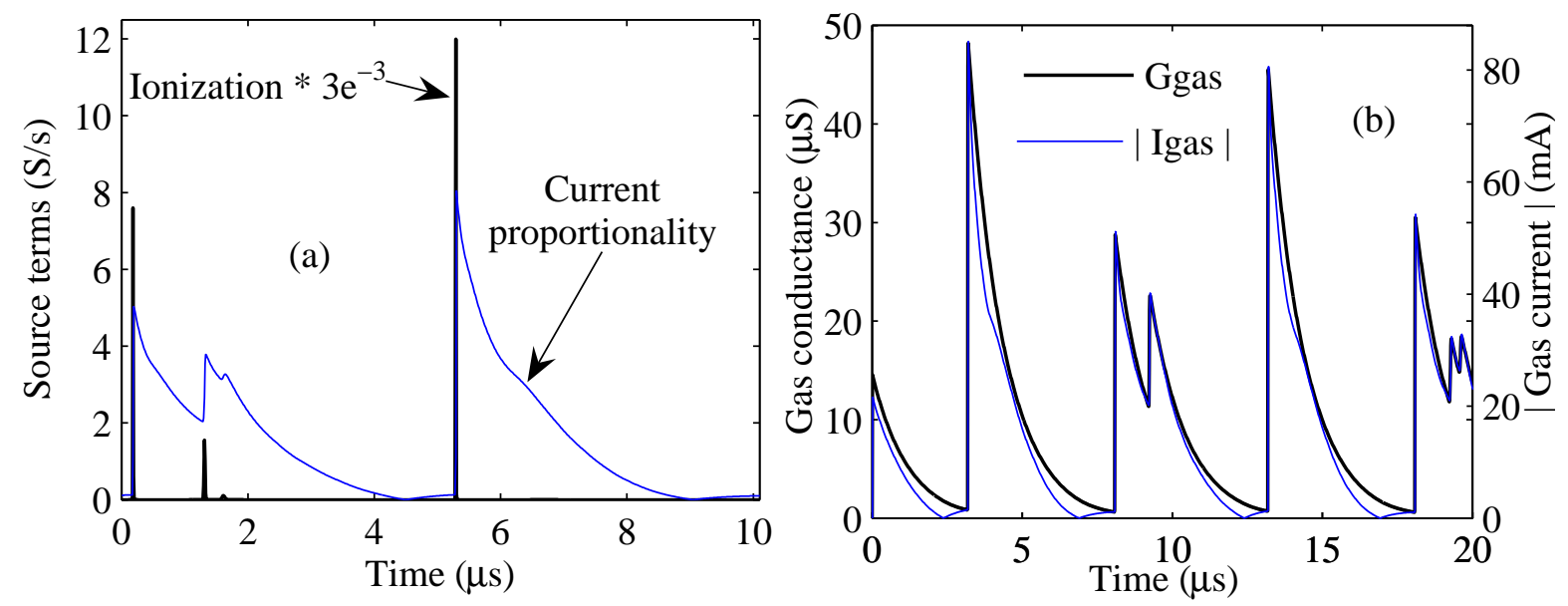

Figure 11. Temporal contribution of the two source terms in the conductance equation for a $100 \mathrm{kHz}$ sine experiment (a). Similitude of the conductance $G$ and the absolute value of the conduction current $\left|I_{\mathrm{g}}\right|$.

\section{Conclusions}

A circuit based model of DBD lamp is proposed; an identification method is developed, intended to approach the initial parameters to the actual values of this model. A specific case is proved with the $\mathrm{XeCl}$ lamp, where the electrical model of a DBD has been developed and demonstrated to be predictive, with several sine and pulsed experiments. PSIM and SABER simulation models have been built and tested with the aim of fast model validation and future power supply design purposes.

\section{Acknowledgments}

The authors thank Dermoptics (Quantel Group) for providing their power supply and patented lamp for the experimental part of the presented work.

\section{References}

[1] U. Kogelschatz, B. Eliasson and W. Egli, Journal de physique 4, C4.47-C4.66 (1997)

[2] A.M. Cassie, GIGRE tech. Report No. 102, 1939

[3] O. Mayr, Electrical Engineering (Archiv fur Elektrotechnik) 37, 508-688 (1943)

[4] S. Bhosle, G. Zissis, J. J. Damelincourt, A. Capdevila, K. Gupta, F. P. Dawson and V.F. Tarasenko, IEEE IAS 1518783, 2315-2319 (2005)

[5] J-P. Salanne, PhD Thesis, INP Toulouse, pp 95-116, 2005 web: http://ethesis.inp-toulouse.fr/

[6] D.W. Marquardt and J. SIAM, Appl. Math. 11, 431-441 (1963)

[7] P.R. Gill, W. Murray and M.H. Wright, Practical optimization, pp 136-137 (Academic Press, London, 1981)

[8] F. Adler and S. Müller, J.Phys.D: Appl.Phys. 33, 1705-1715 (2000)

[9] R.J. Carman and R.P. Mildren, J.Phys.D: Appl.Phys. 36, 19-33 (2003)

[10] Powersym Inc. 2005 PSIM User's guide web: http://www.powersys.fr/

[11] Synopsys 2005 Saber MAST Language Reference manual 